\title{
Packed Supercritical Fluid Chromatography for the Analyses and Preparative Separations of Palm Oil Minor Components
}

\author{
Mei Han Ng*, Yuen May Choo \\ Engineering and Processing Research Division, Malaysian Palm Oil Board, Kuala Lumpur, Malaysia \\ Email: " meihan@mpob.gov.my
}

Received 19 May 2015; accepted 6 July 2015; published 9 July 2015

Copyright (C) 2015 by authors and Scientific Research Publishing Inc. This work is licensed under the Creative Commons Attribution International License (CC BY). http://creativecommons.org/licenses/by/4.0/ c) (i) Open Access

\begin{abstract}
This paper depicts a brief review on the applications of packed supercritical fluid chromatography (SFC) in palm oil analyses and purifications from early 1990s to date. Packed SFC has been used for the analyses of various palm oil components. The analytical separations have also been scaled up to preparative scale that leads to the recovery of high value components from palm oil. This review encompasses both analytical and preparative SFC in the oil palm processing.
\end{abstract}

\section{Keywords}

Palm, Phytonutrients, Minor Components, Supercritical Fluid Chromatography (SFC)

\section{Introduction}

The emerging of supercritical fluid chromatography (SFC) in separation science has grown rapidly in recent years. The unique properties of supercritical fluid as mobile phase in SFC overcome the difficulties of solute thermal instability and volatility encountered in GC and also shorten the relatively longer analyses times of HPLC separations [1]-[5]. Although GC and HPLC are good separating tools in their own ways, the SFC is a more powerful technique in comparison. In addition, it offers a clean, hygienic and healthy working environment which is equally as important as the result of an analysis. The comparatively lower operating temperature of SFC over GC gives the advantage of preserving heat-labile compounds, commonly found in plants [6]-[9]. However, SFC as an analytical tool had a slow start due to some technical deficiencies and depended heavily on the use of capillary columns [10].

Packed column SFC is widely accepted these days as it is more robust and more adaptable to a broader

\footnotetext{
"Corresponding author.
}

How to cite this paper: Ng, M.H. and Choo, Y.M. (2015) Packed Supercritical Fluid Chromatography for the Analyses and Preparative Separations of Palm Oil Minor Components. American Journal of Analytical Chemistry, 6, 645-650. 
sprectrum of compound classes. The development of packed column technologies in recent years has contributed to SFC gaining popularity since. With hurdles such as back-pressure regulation, consistent flow rates, entrainer addition, sample injection, automation, stationary phases, resolved, packed SFC is getting stronger than ever [11]-[16].

Various chromatographic and analytical techniques have been adopted for the analyses of palm oil. Crude palm oil (CPO), which is extracted from the oil palm fruits, is complex on its own with the composition of glycerides (TG > 90\%; DG, 2\% - 7\% and MG, <1\%), FFA (3\% - 5\%) and about 1\% minor components such as the carotenoids (500 - 700 ppm), vitamin E (600 - 1000 ppm), sterols (250 - 620 ppm) and squalene (200 - 600 ppm) [17] [18]. Due to the complexity of CPO, each group of compounds requires specific techniques for their analyses. For instance, palm vitamin E was analysed using HPLC with fluorescence detection, squalene and sterols by GC-FID after saponification, and carotenes by UV-vis spectrophotometry [19] [20]. Chromatographic isolations, e.g. by HPLC and GC, of similar compounds from sources other than palm oil have also been reported [21] [22]. SFC of carotenes, vitamin E and sterols has also been reported in the past using model mixtures. However, it is noteworthy that SFC separations are very much different in real sample matrix compared to model matrixes where interference from other compounds was eliminated.

\section{SFC as Analytical Tool}

Choo and researchers reported on a straight forward SFC, in order of elution, squalene, carotenes, vitamin E and sterols, from real palm oil samples in a single run [23]. The study reported that the analyses using SFC did away with the tedious sample preparations required for each group of the compounds should they be analysed separately using conventional GC and/or HPLC method [23]. Conventional analyses of these palm components were tedious, as different techniques such as UV-vis spectrophotometry, HPLC and GC are necessary to quantify all four groups of these minor components in just one sample [23]. Because different analyses require different sample preparations, such as silylation, to convert non-volatile compounds to their more volatile derivatives for GC analyses, the whole procedure was time consuming and labor intensive. Using normal phase SFC, sample preparation which takes less than 5 minutes, is carried out only once and the analysis was completed in 20 minutes, as opposed to HPLC and GC, which takes up to 45 minutes for completion [23]. The SFC separation of the four groups of palm minor components was carried out with $\mathrm{SC}-\mathrm{CO}_{2}$ as mobile phase with $4 \%$ ethanol as entrainer. Temperature of the column was $50^{\circ} \mathrm{C}$ and pressure $180 \mathrm{~kg} / \mathrm{cm}^{2}$. Coupled with a photodiode array detector, detection of each group of the palm minor components were carried out through UV spectra, $450 \mathrm{~nm}$ for carotenes, $290 \mathrm{~nm}$ for vitamin E and $230 \mathrm{~nm}$ for both squalene and sterols. The same conditions were applied for the analyses of minor components in the residual oil obtained from palm pressed fibre (PFO), which in turn, is the biomass left behind upon pressing of the oil from the oil palm fruits [23]. The concentration of the minor components are much higher in PFO than CPO; carotenoids (4000 - 6000 ppm), vitamin E (2000 - 4000 ppm), sterols (4000 - 6500 ppm) [24].

In the same study, Choo et al. also reported on the application of SFC to separate and quantify the individual vitamin E present in palm oil [23]. All 5 of the vitamin E present, namely $\alpha$-tocopherol, $\alpha$-tocotrienol, $\gamma$ - tocopherol, $\gamma$-tocotrienol and $\delta$-tocotrienol, were separated and quantified using SFC, coupled with a silica column, with results comparable to the conventional HPLC technique which was widely used for the analyses of such compounds. The elution of the individual palm vitamin E followed the order of: $\alpha-\mathrm{T}, \alpha-\mathrm{T}_{3}, \gamma-\mathrm{T}, \gamma-\mathrm{T}_{3}$ and $\delta$-T $\mathrm{Ng}$ et al. also reported on similar findings, both with silica, as well as a diol stationary phase [25] [26]. Of the eight natural vitamin E components, $(\alpha-, \beta$-, $\gamma$ - and $\delta$-tocopherol, $\alpha$-, $\beta$-, $\gamma$ - and $\delta$-tocotrienol), only 5 are present in palm oil. This was confirmed by comparison of real samples with authentic standards of which separation was carried out by SFC using diol column. The elution order of the individual vitamin E by diolcolumm was, $\alpha$-T, $\alpha-\mathrm{T}_{3}, \beta-\mathrm{T}, \delta$-T, $\beta-\mathrm{T}_{3}, \gamma-\mathrm{T}, \gamma-\mathrm{T}_{3}$ and $\delta$-T3. Study carried out by $\mathrm{Ng}$ et al. was also backed by data from nuclear magnetic resonance (NMR) and Mass Spectrometry which confirmed the identity of each of the individual vitamin E present in palm oil [25]. In both stationary phases used, entrainers of $4 \%$ - $6 \%$ were used to facilitate the separation. For normal phase silica, $\mathrm{SC}-\mathrm{CO}_{2}$ is coupled with ethanol as the mobile phase while methyl-tert-butylether was the entrainer for the separation by diol column.

One of the problems associated with the behavior of solutes in supercritical fluid is the changes in the wavelength $\left(\lambda_{\max }\right)$ where they absorb maximum UV. $\lambda_{\max }$ is a useful reference for the identification of carotenes as each individual carotene has their own specific $\lambda_{\max }$ [19] [27]. In supercritical environment, the $\lambda_{\max }$ is affected 
by the temperature, pressure, as well as the type and percentage of entrainer. The changes in $\lambda_{\max }$ is particularly a concern in the analyses of palm carotenes as most of the 11 types of palm carotenes present were identified solely through their $\lambda_{\max }$, in the absence of authentic standards (Table 1) [19] [27]. In the study by Ng et al., $\lambda_{\max }$ of 4 types of palm carotenes, lycopene, phytoene, $\beta$-carotene and $\alpha$-carotene) in different entrainer's environment were investigated and recorded (Table 2) [28]. The study was carried out in normal silica column with temperature $50^{\circ} \mathrm{C}$ and pressure $180 \mathrm{~kg} / \mathrm{cm}^{2}$. Mobile phase was $\mathrm{SC}-\mathrm{CO}_{2}$ with varying percentage of ethanol. It was observed that the $\lambda_{\max }$ of the carotenes shifted to longer wavelength with the increased in entrainer's percentage, regardless the density of SC- $\mathrm{CO}_{2}$. It was concluded that in the supercritical fluid environment, the determining factor for the $\lambda_{\max }$ of the carotenes depended solely on the amount of entrainer present. The shift of $\lambda_{\max }$ to longer wavelength was explained as the bathochromic effect of the molecules whereby polar solutions give longer $\lambda_{\max }$ than non-polar solutions. With the increased percentage of the entrainer, the polarity of the whole mobile phase mixture increased [29]. Thus, it was observed that with higher percentage of entrainer, the $\lambda_{\max }$ shifted to longer wavelength [28].

For applications where water insoluble compounds are concerned, SFC has clear advantages over HPLC. Palm oil, which consists of mainly lipid components has a complex mixture of antioxidative compounds, with coenzyme $\mathrm{Q}_{10}$ being one of them [17] [18]. Coenzyme $\mathrm{Q}_{10}$ or also known as ubiquinone, is a powerful antioxidant that is present in $10-80 \mathrm{ppm}$ in crude palm oil [17] [30]. The importance of coenzyme $\mathrm{Q}_{10}$ is established with the fact that it shows promising results when administered to patients with cardiac or heart diseases. In addition, it has also been shown to be effective in the prevention of lipid peroxidation and oxidative damage in the haemoglobin [31]-[34]. Analyses and detection of coenzyme $\mathrm{Q}_{10}$ was challenging due to its low concentration in CPO. Coupled with pre- treatment of CPO, Ng et al. successfully separated and detected the palm coenzyme $\mathrm{Q}_{10}$

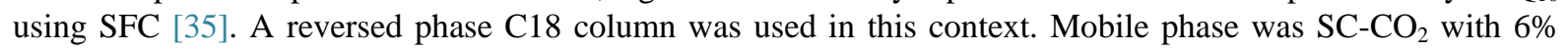
methanol as entrainer. It was readily agreed that SFC is a normal phase chromatographic tool without most of the problems usually associated with normal phase HPLC. The use of reversed phase SFC for the separation of coenzyme Q showed that the technique is equally successful where reversed phase is concerned.

Table 1. Composition of individual carotenes in crude palm oil.

\begin{tabular}{cc}
\hline CAROTENES & CPO (of total carotenes \%) \\
\hline Phytoene & 1.27 \\
Phytofluene & 0.06 \\
$\beta$-carotene & 56.02 \\
$\alpha$-carotene & 35.06 \\
Cis- $\alpha$-carotene & 2.49 \\
$\xi$-carotene & 0.69 \\
$\gamma$-carotene & 0.33 \\
$\delta$-carotene & 0.83 \\
Neurosporene & 0.29 \\
$\beta$-zeacarotene & 0.74 \\
-zeacarotene & 0.23 \\
Lycopene & 1.30 \\
\hline
\end{tabular}

Table 2. $\lambda_{\max }$ of individual carotenes in supercritical $\mathrm{CO}_{2}$ with different percentage of ethanol.

\begin{tabular}{|c|c|c|c|c|c|c|c|c|c|}
\hline \multirow{3}{*}{ Individual Carotene } & \multicolumn{9}{|c|}{$\lambda_{\max }(\mathrm{nm})$} \\
\hline & \multicolumn{9}{|c|}{ Percentage of Ethanol (\%) } \\
\hline & \multicolumn{3}{|c|}{35} & \multicolumn{3}{|c|}{18} & \multicolumn{3}{|c|}{5} \\
\hline Lycopene & 436 & 462 & 490 & 432 & 458 & 488 & 428 & 452 & 480 \\
\hline Phytoene & 275 & 287 & 297 & 273 & 285 & 295 & 273 & 285 & 295 \\
\hline$\beta$-carotene & 419 & 446 & 468 & 413 & 440 & 462 & 411 & 436 & 460 \\
\hline$\alpha$-carotene & 413 & 438 & 462 & 409 & 434 & 460 & 405 & 430 & 456 \\
\hline
\end{tabular}




\section{Preparative SFC}

Preparative SFC is deemed to be a 'greener' alternative to preparative chromatography as it eliminate the use of extensive amount of organic solvents [9] [15]. The use of SFC for preparative separations has received considerable interest as a tool for pre-clinical purification for bioactives [36]-[39]. Current instrumentation for the preparative purification using SFC is quite similar to that of HPLC. Direct scale up of analytical separation of oil palm components to preparative scale was made possible and reported by Choo et al. [40]. In the study, Choo et al. successfully carried out separation and recovery of triglycerides, diglycerides, free fatty acids, carotenes and vitamin $\mathrm{E}$ in palm oil samples using both normal and reversed phase columns, with the similar elution order as that of analytical separations [40].

A preparative SFC purification of palm oil mixture also saw the separation, purification and recovery of individual vitamin $\mathrm{E}$ [41]. In this process, the individual vitamin E, as a mixture, was separated and recovered in high purity. The individual vitamin E are high value compounds due to their beneficial health properties [42]-[45].

The main concern of preparative SFC is the cost. While hardware instrumentations can be directly adapted from preparative LC, the consumables; i.e. mobile phase, incurred an exorbitant operational cost. The cost can be reduced with the introduction of a mobile phase recycling system in which both the supercritical fluid, as well as, the entrainer (if any) is recycled in a close loop system.

\section{Conclusion}

The development of packed SFC has made paved the way for its wider applications in the oil palm industry, from analysis to preparative separation and recovery of high valuable compounds.

\section{Acknowledgements}

The authors wish to thank the Clean and Emerging Technologies Group for the assistance in the preparation of this paper.

\section{References}

[1] Smith, R.M. (Ed.) (1998) Supercritical Fluid Chromatography. Royal Society of Chemistry, Athenaeum Press, Cambridge, UK.

[2] Smith, R.M. (Ed.) (1993) Supercritical Fluid Chromatography, RSC Chromatography Monographs. Royal Society of Chemistry, London.

[3] Majewski, W., Valery, E. and Ludemann-Hombourger, O. (2005) Principle and Applications of Supercritical Fluid Chromatography. Journal of Liquid Chromatography \& Related Technologies, 28, 1233-1252. http://dx.doi.org/10.1081/JLC-200053039

[4] Chester, T.L. (1986) The Role of Supercritical Fluid Chromatography in Analytical Chemistry. Journal of Chromatographic Science, 24, 226-229. http://dx.doi.org/10.1093/chromsci/24.6.226

[5] Gere, D.R.; Houck, R.K.; Pacholec, F. and Rosselli, A.C.P. (1998) Supercritical Fluid Chromatography: A Technology Update. Fresenius' Zeitschrift für analytische Chemie, 330, 222-224. http://dx.doi.org/10.1007/BF00515610

[6] King, J.W. and List, G.R. (1996). Supercritical Fluid Technology in Oil and Lipid Chemistry. AOCS Press, Champaign.

[7] Laakso, P. (1992) Supercritical Fluid Chromatography of Lipids. In: Christie, W.W., Ed., Advances in Lipid Methodology, One Oily Press, Dundee.

[8] Yarita, T., Nomura, A., Kouichi, A. and Takeshita, Y. (1994) Supercritical Fluid Chromatography Determination of Tocopherols on an ODS-Silica Gel Column. Journal of Chromatography A, 679, 329-334. http://dx.doi.org/10.1016/0021-9673(94)80575-X

[9] Taylor, L.T. (1997) Trends in Supercritical Fluid Chromatography. Journal of Chromatographic Science, 35, $374-382$. http://dx.doi.org/10.1093/chromsci/35.8.374

[10] Chester, T.L. and Pinkston, J.D. (2004) Supercritical Fluid Chromatography. Analytical Chemistry, 76, 4606-4613. http://dx.doi.org/10.1021/ac040088p

[11] Roman, J.M., Abbot, E., Xu, X., Fox, S.D., Veenstra, T.D. and Issaq, H.J. (2007) Optimization of Experimental Parameters for Packed Column Supercritical Fluid Chromatography. Journal of Liquid Chromatography \& Related Technologies, 30, 2037-2044. http://dx.doi.org/10.1080/10826070701435046 
[12] Harris, C.M. (2002) Product Review: The SFC Comeback. Analytical Chemistry, 74, 87A-91A. http://dx.doi.org/10.1021/ac0219391

[13] Berger, T.A. (1995) Packed Column SFC. Royal Society of Chemistry, Letchworth.

[14] Sandra, P., Medvedovici, A., Kot, A. and David, F. (1998) Selectivity Tuning in Packed Column Chromatography. In: Anton, K. and Berger, C., Eds., Supercritical Fluid Chromatography with Packed Columns, Marcel Dekker, Inc., New York, 161-194.

[15] Taylor, L.T. (1990) Packed Column Development in Supercritical Fluid Chromatography. Journal of Chromatographic Science, 28, 357-366. http://dx.doi.org/10.1093/chromsci/28.7.357

[16] Wei, Z., Dorsey, J.G. and Chester, T.L. (2000) Modifier Effects on Column Efficiency in Packed Column Supercritical Fluid Chromatography. Analytical Chemistry, 72, 3620-3626. http://dx.doi.org/10.1021/ac991417u

[17] Goh, S.H., Choo, Y.M. and Ong, A.S.H. (1985) Minor Constituents of Palm Oil. Journal of the American Oil Chemists' Society, 62, 237-240. http://dx.doi.org/10.1007/BF02541384

[18] Tay, B.Y.P. and Choo, Y.M. (2000) Valuable Minor Constituents of Commercial Red Palm Olein: Carotenoids, Vitamin E, Ubiquinones and Sterols. Journal of Oil Palm Research, 12, 14-24.

[19] Tay, B.Y.P. and Choo, Y.M. (2000) Practical Guide to Establishing Palm Carotenoids Profile by HPLC with Three Dimensional Diode Array Detector. Palm Oil Developments, 22, 13-17.

[20] Ye, I., Landen, W.O. and Eitenmiller, R.R. (2001) Comparison of the Column Performance of Narrow Bore and Standard Bore Columns for the Chromatographic Determination of $\alpha$-, $\beta$-, $\gamma$ - and $\delta$-Tocopherol. Journal of Chromatographic Science, 39, 1-6. http://dx.doi.org/10.1093/chromsci/39.1.1

[21] Villen, J., Blanch, G.P., del Castillo, M.L.R. and Herraiz, M. (1998) Rapid and Simultaneous Analysis of Free Sterols, Tocopherols, and Squalene in Edible Oils by Coupled Reversed-Phase Liquid Chromatography-Gas Chromatography. Journal of Agricultural and Food Chemistry, 46, 1419-1422. http://dx.doi.org/10.1021/jf970706l

[22] Senorans, F.J., Tabera, J. and Herraiz, M. (1996) Rapid Separation of Free Sterols in Edible Oils by On-Line Coupled Reversed Phase Liquid Chromatography-Gas Chromatography. Journal of Agricultural and Food Chemistry, 44, 31893192. http://dx.doi.org/10.1021/jf960071a

[23] Choo, Y.M., Ng, M.H., Ma, A.N., Chuah, C.H. and Hashim, M.A. (2005) Application of Supercritical Fluid Chromatography in the Determination of Palm Squalene, Carotenes, Vitamin E and Sterols in Palm Oil. Lipids, 40, 429-432. http://dx.doi.org/10.1007/s11745-006-1400-6

[24] Choo, Y.M., Yap, S.C., Ooi, C.K., Ma, A.N., Goh, S.H. and Ong, A.S.H. (1996) Recovered Oil from Palm-Pressed Fiber: A Good Source of Natural Carotenoids, Vitamin E, and Sterols. Journal of the American Oil Chemists' Society, 73, 599-602. http://dx.doi.org/10.1007/BF02518114

[25] Han, N.M., May, C.Y., Ngan, M.A., Hock, C.C. and Ali Hashim, M. (2004) Isolation of Palm Tocols Using Supercritical Fluid Chromatography. Journal of Chromatographic Science, 42, 536-539.

[26] Han, N.M., May, C.Y., Ngan, M.A., Chuah, C.H. and Ali Hashim, M. (2004) Separation of Vitamin E (Tocopherol, Tocomonoenol and Tocotrienol) from Palm Oil. Lipids, 39, 1031-1035. http://dx.doi.org/10.1007/s11745-004-1327-y

[27] Yap, S.C., Choo, Y.M., Ooi, C.K., Ong, A.S.H. and Goh, S.H. (1991) Carotenes in the Oil from Different Palm Species. Elaies, 8, 369-378.

[28] Ng, M.H., Choo, Y.M., Ma, A.N., Hashim, M.A. and Chuah, C.H. (2006) Isolation and Identification of Individual Palm Carotenes Using Supercritical Fluid Chromatography. Malaysian Journal of Science, 25, 139-145.

[29] Mendes, R.L., Nobre, B.P., Coelho, J.P. and Palavna, A.F. (1999) Solubility of $\beta$-Carotene in Supercritical Carbon Dioxide and Ethane. The Journal of Supercritical Fluids, 16, 99-106. http://dx.doi.org/10.1016/S0896-8446(99)00029-7

[30] Hamid, H.A., Choo, Y.M., Goh, S.H. and Khor, H.T. (1995) The Ubiquionones of Palm Oil in (Ong, Niki and Packer Eds) Nutrition, Lipids, Health and Disease. AOCS Press, Urbana.

[31] Blizkanov, E.G. and Hunt, G.L. (1987) The Miracle Nutrient Coenzyme Q10. Bantamn Book, New York.

[32] Ernster, L. (1977) Facts and Ideas about the Function of Coenzyme Q in the Mitochondira. In: Folkers, K. and Yamamura, Y., Eds., Biomedical and Clinical Aspects of Coenzyme Q, Elsevier, Amsterdam.

[33] Beyer, R.E. (1989) The Role of Coenzyme Q in Free Radical Formation and Antioxidation. In: Minguel, J., Quinanilha, A.T. and Weber, H., Eds., CRC Handbook of Free Radicals and Antioxidants in Biomedicine, Volume II, CRC Press, Inc., Boca Raton, pp.

[34] Mellons, A. and Tappel, A.L. (1996) The Inhibition of Mitochondrial Peroxidation by Ubiquinone and Ubiquinol. The Journal of Biological Chemistry, 241, 4353-4356.

[35] Han, N.M., May, C.Y., Ngan, M.A., Hock, C.C. and Ali Hashim, M. (2006) Separation of Coenzyme Q10 in Palm Oil by Supercritical Fluid Chromatography. American Journal of Applied Sciences, 3, 1929-1932. 
http://dx.doi.org/10.3844/ajassp.2006.1929.1932

[36] Tan, T.Q., Orihuela, C. and Swanson, D. (2008) The Application of Preparative Batch HPLC, Supercritical Fluid Chromatography, Steady State Recycling, and Simulated Moving Bed for the Resolution of a Racemic Pharmaceutical Intermediate. Chirality, 20, 139-146. http://dx.doi.org/10.1002/chir.20512

[37] Wu, D.R., Leith, L., Balasubramaniam, B., Palcic, T. and Wang-Iverson, D. (2006) The Impact of Chiral Supercritical Fluid Chromatography in Drug Discovery: From Analytical to Multi-Gram Scale. American Laboratory (June/July 2006), 24-26.

[38] Ramirez, P., Santoyo, S., Garcia-Risco, M.R., Senorans, F.J., Ibanez, E. and Reglero, G. (2007) Use of Specially Designed Columns for Antioxidants and Antimicrobials Enrichment by Preparative Supercritical Fluid Chromatography. Journal of Chromatography A, 1143, 234-242. http://dx.doi.org/10.1016/j.chroma.2006.12.096

[39] Ramirez, P., Garcia-Risco, M.R., Santoyo, S., Senorans, F.J., Ibanez, E. and Reglero, G. (2006) Isolation of Functional Ingredients from Rosemary by Preparative Supercritical Fluid Chromatography (Prep-SFC). Journal of Pharmaceutical and Biomedical Analysis, 41, 1606-1613. http://dx.doi.org/10.1016/j.jpba.2006.02.001

[40] Choo, Y.M., Ma, A.N., Hawari, Y., Yamauchi, Y., Bounoshita, M. and Saito, M. (1996) Separations of Crude Palm Oil Components by Semi Preparative Supercritical Fluid Chromatography. Journal of the American Oil Chemists' Society, 73, 523-525. http://dx.doi.org/10.1007/BF02523930

[41] Choo, Y.M., Ma, A.N. and Basiron, Y. (2000) Method of Chromatographic Isolation for Non-Glyceride Components. US Patent No. 6586201.

[42] Qureshi, A.A., Mo, H.B., Packer, L. and Peterson, D.M. (2000) Isolation and Identification of Novel Tocotrienols from Rice Bran with Hypocholesterolemic, Antioxidant and Antitumor Properties. Journal of Agricultural and Food Chemistry, 48, 3130-3140. http://dx.doi.org/10.1021/jf000099t

[43] Goh, S.H., Hew, N.F., Norhanom, A.W. and Yadar, M.C. (1994) Inhibition of Tumour Growth Promotion by Various Palm Oil Tocotrienols. International Journal of Cancer, 57, 529-531. http://dx.doi.org/10.1002/ijc.2910570415

[44] Nesaretnam, K., Khor, H.T., Ganesan, J., Chong, Y.H., Sundram, K. and Gapor, A. (1992) The Effect of Vitamin E Tocotrienols from Palm Oil on Chemically Induced Mammary Carcinogenesis in Female Rats. Nutrition Research, 12, 63-75. http://dx.doi.org/10.1016/S0271-5317(05)80410-5

[45] Fu, J.Y., Zhang, W., Blatchford, D.R., Tetley, L., Mac Connel, G.M. and Dufes, C. (2011) Novel Tocotrienol-Entrapping Vesicles Can Eradicate Solid Tumors after Intravenous Administration. Journal of Controlled Release, 154, 20-26. http://dx.doi.org/10.1016/j.jconrel.2011.04.015 